\section{Innovations in Financial Audit Based on Emerging Technologies}

Lavinia Mihaela CRISTEA, Ph. D. Student, The Bucharest University of Economic Studies, Romania, e-mail: cristealaviniamihaela@yahoo.com

\section{Anstract}

In the context of assessing the impact of IT concern on financial audit missions, the purpose of this paper is to investigate how new Big Data technologies shape the auditor profession, the methods and tools used.

Motivation: technology has put its mark on all fields of activity and professionals tend, step by step, to experiment within auditing by testing new technologies; taking into account the hypothesis of large-scale adoption of modern technologies offered by IT, Big Data development and Data Analytics (BDA) represent a highly interesting case, on which the author pleads for debating. The two qualitative and fundamental research methods, together with the critical observation that consisted in manual selections of the online publications of the professional bodies in audit and accounting, the specialized literature and discussions with IT and audit Big Four specialists support the analysis of Big Data impact, completing previous specialized papers, given the fact that the need for (extended) documentation in this regard is further pointed out. The results of this investigation propose Data Analytics, Hadoop, NoSQL as Big Data top technologies applicable on financial audit missions, in order to simplify audit procedures, improve the organizational performance and reduce the level of risk.

Keywords: financial audit; Big Data; Data Analytics; Hadoop; NoSQL; emerging technologies mapped to audit

JEL Classification: M42, 033

To cite this article:

Cristea, L.M., (2020), Innovations in Financial Audit based on

Emerging Technologies, Audit Financiar, vol. XVIII,

no. 3(159)/2020, pp.513-531,

DOI: 10.20869/AUDITF/2020/159/016

To link this article:

http://dx.doi.org/10.20869/AUDITF/2020/159/016

Received: 22.02.2020

Revised: 9.03.2020

Accepted: 25.05.2020 


\section{Introduction}

Big Data will change the world (ISACA, 2018 a); Chan et al., 2018), this was the conclusion following the survey conducted in 2014 (61\%) and 2018 (53\%). ACCA (2019) argues that technology has the potential to revolutionize the audit and the analyzes that require the purpose of this process, analyzes which are high volumes of data (i.e. Big Data). Big Data proposes an avalanche of changes in the business models, the adoption of an automated trend and the acquisition of new prospective approaches from the professionals, in order to embrace the opportunities but also to face the challenges generated by the IT impact. For auditors, the evolutions in technology require documentation and technological preparation (Rîndașu, 2016) in order to perform a high-quality audit.

Given the fact that the Big Data technological phenomenon and the technologies that derive from this field have not been explained so far to all stakeholders, present and future users of modern technology, this work complements the research direction proposed by Appelbaum (2017) to deepen the impact of Big Data and Data Analytics (BDA), an area of research analyzed over extended periods of time (Moffitt \& Vasarhelyi, 2013; Goes, 2014; Krahel \& Titera, 2015; Vasarhelyi et al., 2015; Klous \& Wielaard, 2016; Alles et al., 2016; ISACA Journal, 2018; Salijeni et al., 2018; Gepp et al., 2018; ACCA, 2019) with whom the author aspirate to contribute by initiating discussions on this topic, namely (1) how these technologies can be mapped on financial audit missions, (2) which are their particularities and (3) why are suitable for the auditing profession. Blockchain, RPA, Al, Machine Learning and the Deep Learning subset will be analyzed in a forthcoming article "Emerging IT Technologies for Accounting and Auditing Practice", following the same methodological approach.

Specifically, this paper aims to contribute to the current research by: (1) developing technical notions of BDAs based on qualitative research and (2) understanding how BDA technologies can be integrated into the financial audit missions. In this regard, we considered a fundamental research process, conducted through debates with IT and audit specialists of Big Four companies. From a technical point of view, the development of the notion of these emerging technologies in the financial audit is based on the extended documentary research, by critically examining specialized literature, topic debates, data sources with technical explanations (i.e. books, websites), technological audit reports issued by the Big Four companies (i.e. KPMG, PwC), reports and journals issued by professional bodies and organizations in the financial and IT field (i.e. ACCA, ISACA, AICPA). The integration of these technologies in the financial audit missions is proposed by the author, being illustrated through representations of (practical) schemes that highlight the technological processes, mathematical algorithms and factors that influence the results of running scripts that define the software (Chan et al., 2018). Although in Big Four companies the applicability of BDA is in the development stage, and still at the level of documentation for larger analyzes and implicitly, more precisely, the author hopes that this research will find answers to 4 important points, on which the business environment seeks for answers:

- What will be the technological impact of BDA development for financial audit missions?

- How emerging BDA technologies can be mapped in these missions?

- What is the working mechanism (of these technological innovations) and what are the algorithms involved in data analysis?

- Currently, what is the role of the auditor? Is there a professional redefinition?

This article can contribute with concrete examples for the interested public and debate initiations regarding the emerging technologies functionality and their mapping (where applicable) on financial audit missions. For Romania, the financial audit is the coordinating form for all types of audit. The general audit rules are issued by the Chamber of Financial Auditors of Romania and are considered reference criteria for any type of audit.

The examination of the reports issued by the Big Four companies and the professional bodies has as main objective the highlighting of IT impact that must be embraced by the auditors. According to current estimates, by 2025 , international companies specializing in audit and consulting services (i.e. Big Four) will hold a substantial share of the audit market (Bhaskar and Flower, 2019). I consider that the examination of these reports represents a solid foundation for the chosen topic, together with the qualitative research of the specialized literature and fundamental technical documentation (books, websites) realized through critical observations, selecting only the necessary information. The present study follows trends, actions 
and predictions in the financial audit, but also factors involved in the analysis and decision-making process. The present paper can be useful for the young generation who intend to follow this profession, but also for actual auditors, to adapt to new requirements and to assimilate new technical working skills.

\section{Analysis of literature and snecialized publications}

In the context of confidence restoring in the effectiveness of this process (i.e. financial audit) following the Enron Corporation, Carillion economic scandals (Bhaskar and Flower, 2019), the SarbanesOxley Act (SOX) was adopted in 2002 in order to ensure the accuracy of financial information. Thus, the financial audit examines the compliance of financial statements with the international accounting standards (IAS) and the international auditing standards (ISA), to express the audit opinion. From Sarbanes-Oxley and till present, the quality of the financial audit has been considerably improved. In this era of emerging technologies, auditing is an ever-changing profession since technology impacts all areas of this profession (Chan et al., 2018; Schmitz \& Leon, 2019).

In the context of confidence restoring in the effectiveness of this process (i.e. financial audit) following the Enron Corporation, Carillion economic scandals (Bhaskar and Flower, 2019), the SarbanesOxley Act (SOX) was adopted in 2002, in order to ensure the accuracy of financial information. Thus, the financial audit examines the compliance of financial statements with the international accounting standards (IAS) and the international auditing standards (ISA), to express the audit opinion. From Sarbanes-Oxley and till present, the quality of the financial audit has been considerably improved. In this era of emerging technologies, auditing is an ever-changing profession since technology impacts all areas of this profession (Chan et al., 2018; Schmitz \& Leon, 2019).

Looking at the past, the financial crisis (2006-2010) was the first impulse that "pushed" companies to pay greater attention to the presentation of financial statements and the adoption of advanced professional skepticism by the auditors, ensuring the accurate representation and the absence of errors in the declared amounts. Later, the introduction of IFRS as an international financial reporting standard for all listed companies in the EU, while the option of converging with IFRS for listed and unlisted companies, without equity investments, is the second argument favoring the paradigm shift in audit missions. Starting with the XIX century, the emergence and development of technology is the third aspect that favors recent discoveries in the working methods of this profession. By the emergence and development of technology, we understand that IT ensures the integrity of information systems and financial reporting, in order to prevent economic-financial crises. The opinion of investors, auditors, CEOs, CFOs and stakeholders is that IT improves audit activity and helps in increasing the quality, accuracy of results and the allocation of shorter working time for financial data analysis (PwC, 2019).

From 2000-2010 years, the audit has encountered a period of progress due to the intense development of technology. Distributed Computing enables data storage in the Cloud and the use of IT software that processes data in a virtual environment. Between 2010-2020, Big Data appears and develops in the fields of accounting and auditing (Vasarhelyi and Kogan, 2015; Moffitt and Vasarhelyi; 2013), during which various audit software (e.g. CIEL Audit and Review, Gaudit) appear. These software supports the financial auditor in order to carry out the audit activities, creating a hybrid environment in which the systems are responsible for monitoring a voluminous external data environment (Krahel and Vasarhelyi, 2014).

According to the survey conducted by ISACA (2018, b), $94 \%$ of the interviewees are aware of the change in the financial sector and $62 \%$ believe that auditing will become a more IT-oriented profession, this mention represents the second controversial hypothesis of this paper, contrary to KPMG (2018) where it is argued that the methodology of applying the audit should not necessarily be adapted to Big Data, as IT is not absolutely necessary in methodological procedures. The acquisition of IT skills and working abilities better than in present are foreseen in the future of this activity sector. IT audit or IT audit systems is a process that allows the hardware and software infrastructure evaluation of the audited company. The IT audit is necessary in establishing the resources-needs connection and verifies the compliance with the working procedures, the way of using the software, the existence of the IT equipment and the existing configurations of the client's network.

For an IT auditor, any audit mission is based on the verification of general IT controls, such as: the correct 
functionality of the technologies implemented, the hardware and software infrastructure of the audited company, and the granting of access rights. The financial auditor verifies the recording of transactions in the computer system according to the original documents, representing the accounting basis record. The verification action represents the financial audit essence, that is why it is possible that this term (i.e. of verification) to be frequently encountered in this paper. By following the application of specific standards, reporting frameworks or audit guides, the compliance of the financial statements is verified (Rozario \& Thomas, 2019), while the IT audit will be responsible with user rights verification, access or modification/ deletion of access right as a result of hiring, changing the company's position or resignation, the access password integrity, the hardware and software organizational components infrastructure, the list of active and inactive users and implicitly the creation of IT tickets to the support department.

This type of audit involves responsibilities and specific technical skills. The IT audit consists of studying the client's network, analyzing existing licenses, organizing the software legalization process, identifying errors, analyzing infrastructure deficiencies, recommendations and suggestions for optimizing the company system, drawing up the organizational plan, developing long-term strategies that are envisaged the virtual prototype identified from the analyzed infrastructure. Are analyzed the activities carried out by companies, due to the use of complex ERP systems, the implementation of the services provided by Cloud (e.g. Hybrid Cloud, Private Cloud), but also the adoption of other business models (e.g. remote type connection through the Remote Desktop Protocol - RDP application or the adoption Bring Your Own Device BYOD solutions.

The future signals on changes in the auditor profession, namely a new perspective of the auditor: an IT-based audit, with the objective of certifying the company's transactions, assurances on the correct implementation of information technologies. Especially in Big Four companies, the audit has become an IT audit or continuous audit or hybrid audit, where the IT auditor performs general IT controls, such as granting user rights, access or deletion of access rights following the status change:
- employment, change in company's position or resignation (i.e. a list of changes), but also the existence of the IT ticket regarding these changes;

- the list of active and inactive users, through a fast verification with $\mathrm{HR}$ department;

The IT audit aims to comply with internal regulations, such as the password user access integrity at the company level, provided in a folder (e.g. Active Directory).

Example: In the company's security policies, certain rules of internal procedure are specified, such as: the length of a password to be greater than 12 characters, at least two characters to be set in upper case, at least two special characters, and based on the password history, not allowing the same password to be set, in addition, the frequency of change to occur at least once a calendar month. Password history means that you cannot set popescu12345, given that the previous password was popescu1234, the system only allowing the password to be set as popescu5678. Through this audit test, which is called Test of 1 (in Big Four companies), the IT auditor examines compliance with this internal organizational procedure.

Currently, analyzing the impact of information technology on the audit practice and the auditor profession has become more than a necessity. Auditing in the presence of technology and efficient use of data analysis techniques are two essential features for meeting the audit objectives (Pathak, 2005). At the organizational level, there will be restructuring at the process level, the working mode at the procedural and practical level will be different, the constitution of the audit teams will be aimed at a balanced percentage of accounting specialists, auditors, IT and experts in Data Analytics, which will lead to the emergence of new work tasks and the redefinition of this profession (ISACA, 2018 b).

Financial auditors need to understand the new BDA technologies and to translate them into the audit mission stages. To ensure and protect the quality of the audit, it is necessary to improve IT skills (Janvrin and Wood, 2016; Omoteso, 2016). In order to acquire these skills and learn the specific competencies in the information technology sector, auditors will need training, IT professional training and improvement in the processes performed. The analysis and reflection on the changes in the profession in order to acquire the necessary skills 
represent actions that must be learned (Stanciu, 2015; Chan et al., 2018; Farcane and Deliu, 2020). Proper professional training contributes to improving the standard of audit activity (Salijeni et al., 2018) and establishing a more controlled working environment. Developing emotional intelligence in order to establish a closer connection with clients, in addition to acquiring the technical skills of working in coding, cryptography and hashing, are future aspects, which should be considered by the auditors, for learning and adaptation vision.

The dynamics of IT brings opportunities and risks in the financial audit missions, which denotes a relationship of divergence, opportunity-risk, "imposed" through the development of IT. Traditional auditing continues to change following the implementation of advanced ERP systems, increasing online transactions, Cloud technology and rapid access to data and information (ACCA, 2019), representing opportunities generated by IT dynamics, followed by sophisticated cyber-attacks, representing the risks that organizations face. For a better understanding of the aforementioned IT effects, the author will explain how these new information technologies work and how they contribute to changing the auditor's traditional way of working. The audit procedures and tests applied in the financial audit will evolve significantly, starting with the method of sampling historical information, $100 \%$ auditing the transactions, in real-time or at frequent intervals, favoring the emergence of continuous audit (Chan et al., 2018; Schmitz \& Leon, 2019). Thus, we are witnessing a high degree of automation of the technology that has led to a process of obtaining current, real and relevant data. The full verification of transactions is due primarily to the development of ERP systems.

Since the 1990s, the adoption of ERP has undergone a period of rapid expansion. The Enterprise Resource Planning (ERP) platform gathers all the processes of the company and allows the data flow available to the platform users. Due to the various modules (e.g. Administration, Control, Accounting, Nomenclature, Reports, etc.), ERP systems automate and standardize the operational processes, contribute to the efficiency of the working time and ensure integrated management of the activities through the access to a common database. This database uses standardized data as a result of common definitions and experiences of ERP users. These basic concepts establish connections with defined processes of the company, specified by the workflows of the business departments (e.g. Finance, Human Resources, Operations), facilitating the connection between the user and the system.

The basic principle of ERP consists of the centralized collection of data for accessing them, data that are obtained from several activities and from all ERP users. Data registration is performed either by entering the data by the operators, transfer between third parties or importing from other databases. Over time, the implementation costs have increased and the hardware resources have proved insufficient to keep up with the needs of the organizations, due to the development of technology and new security requirements (e.g. the emergence of vulnerabilities at the computer system level, cyber-attacks, hacking).

More recently, starting with the new millennium, the Cloud is emerging as the main delivery mechanism for new technologies: Blockchain, Al, Machine Learning, Cognitive Computing, intelligent process automation and Internet of Things (loT). Blockchain, Al, Robotic Process Automation, Machine Learning and Deep Learning subset technologies will be researched and designed on financial audit missions in a forthcoming article "Emerging IT Technologies for Accounting and Auditing Practice", the author also contributing by analyzing other technologies what can be adaptable in this area.

The System as a Service (SaaS) delivery model for ERP enables the execution of services on a network of remote servers. The IT infrastructure is stored outside the company. The Cloud provider has control in the integration of the applications, the updating and development of the best functionalities, necessary to run and maintain the company in the competitive environment. The ERP Cloud service provider is responsible for managing the IT infrastructure, integrating software applications and developing new system properties. The assimilation of a Cloud model has become necessary for companies wishing to continue their business, opting for a software update several times a year, at the expense of a costly upgrade that takes place over a longer period of time, between 5 and 10 years. However, companies are reluctant to migrate to a public cloud and prefer hybrid cloud architectures. This choice is due to the combination of the classic benefits of public media and internal control, being found in a Hybrid Cloud. 
An ERP Cloud requires a constant Internet connection to access hardware and software at any time. ERP SaaS works through a network, more precisely through a property lease system, which is not conditioned by Cloud technology. Both solutions are advantageous in terms of the initiation method, although, financially speaking, ERP SaaS could outweigh the cost of an ERP Cloud if the organization opted to purchase the license from the outset. Moreover, in a Cloud system, the data security would be up to the Cloud provider, who is responsible for implementing a secure and efficient technology.

Starting with 2000, Doug Laney presents the term Big Data by joining three elements: volume (i.e. data collection from various sources and storage of massive data), speed (i.e. speed and shorter processing time), variety of data (i.e. structured data, unstructured, digital, email, video, audio, financial transactions). These characteristics were followed by the veracity of the data (i.e. the uncertainty that requires verification) and their value, deduced from the data analysis (Saha, 2014). Data variety is an important feature of Big Data due to the collection of data from various sources (e.g. social media, Web, mobile platforms, corporate systems). The variety in data helps companies in detecting economic trends, but also in establishing links between transactions, facilitating the procedure of conducting the financial audit.

Due to the benefits offered, Big Data investments seek to maximize management in each company. Big Data does not answer the question "why?" it happens, but to the question "what?" it happens. Big Data offers answers and solutions to many requests and challenges from customers or management. Big Data is an invaluable filter for future causal analysis and contributes to the appreciation of the world in which we live in a much more complex way than has ever been perceived (Klous \& Wielaard, 2016).

Today, through Big Data, companies have the opportunity to keep and collect a lot of information, which in the past was practically unavailable. This information is collected from internal sources, based on past records or old searches by the company. In addition, devices used daily, at the individual or organizational level, constantly use data to collect information and perform various functions.

Example: When a user first visits a website, a cookie (i.e. message in a text file) is loaded by the webserver on the user's browser, a cookie identified by a unique ID, which allows identification of preferences in the following visits. This action is repeated on the server page and through the browser, whenever the user visits a website. Once this (collected) information has been identified, it will be possible to connect the user to information already stored on his profile, which results in preferential browsing.

Big Data is due to the increase in the number of transactions, both online and offline. Computer programs contribute to the processing of structured, semi-structured and unstructured data, processing them quickly and accessing any kind of service, at any time. This software is based on algorithms that process information at a phenomenal speed (Chan et al., 2018). The decision is calculated by computers that make the connection with the user's request in a very short time.

Example: For any company, the digital transactions performed are constantly increasing. Any transaction, payment or action by the Internet user contains information, which is subsequently processed through a self-service network. Most of the time, a transaction is based on sub-transactions. An interaction with a client is often constituted of sub-transactions, that is, many points that are moving between a starting point (e.g. ATM, other self-service devices) and an endpoint (i.e. the host authorization).

Another factor that has contributed to the growth of online transactions is the emergence and (unlimited) connection to the Internet, a service that is currently available at an affordable price. Easy access to the Internet is due to the development of efficient infrastructures and technologies that allow continuous navigation and fast data transfer. The Internet is the growth proof of online transactions and hence the emergence and development of Big Data. The data resulting from transactions helps to prepare reports, situations or statistics, which can be found in any type of data (e.g. structured, unstructured, semi-structured) and in any format (i.e. image, sound, video, text etc.), providing auditors indications and answers to questions such as:

1. Were there any changes in the process of completing the transaction from the ATM?

2. Did the transactions take place in a normal way or not? If not, what has prevented the normal flow of money withdrawal? 
3. Was the working procedure followed before cash withdrawal to the client (the existence of a balance greater than or equal to the amount withdrawn from his account)?

4. If an unauthorized card was introduced in the ATM, what does it seem it was not issued by an authorized bank, what were the measures taken?

\section{Research methodlology}

At the micro-level, the paradigm shift brought about by the IT effect in auditing is known at a superficial level. The specialized literature strives to define in a concrete way the impact of IT on financial audit missions. Thus, in order to define this phenomenon as accurately as possible, it is necessary to go through some preliminary steps, necessary in explaining this technological trend and in clarifying a few essential aspects towards: understanding the new technologies, analyzing the data, being familiar with the stages in the financial audit missions and learning the rationale professional auditor. In order to understand the acceptance of the IT effect in this type of audit, it might be considered the deepening of several specialized areas, such as: accounting, business valuation (i.e. calculation and pricing, estimating the company fair value), economic-financial analysis, financial audit, computer systems for management database. Achieving this knowledge, in addition to international auditing and accounting standards, expressing value judgments and applying professional judgment would integrate a supportive research framework in understanding this topic: "Innovations in financial audit based on emerging technologies".

In order to achieve this objective, the author has adopted two types of research, namely qualitative research and fundamental research, considered the most appropriate to achieve the objectives mentioned in the first section of this paper. The impact of IT debated by the specialized literature and the professional accounting and auditing bodies, together with the discussions controlled with IT and auditing Big Four specialists, allowed to create a fundamental connection type, through fundamental and qualitative strategies. Through the qualitative research, I have fixed the technology - financial intercorrelation, interpreted the information of the existing structures and relationships with the way of conducting an audit mission of Big Four companies and transposed them into schema-like information flows. Quantitative research would not have provided sufficient information, more precisely a comprehensive perspective on the approach that is intended to be demonstrated for the purpose of the present study, limited to a data set, limited in providing sufficient information about the reasons that are the basis for the BDA adoption. The occasion of the qualitative research adopted in this paper is due both to the fundamental research and to the critical observation of the author, along with the way of selecting the scientific papers that highlight controversial hypotheses from the specialized literature, professional bodies, but also the applicability of Big Data technologies in financial audit, following discussions with Big Four specialists in the interest areas of this paper, audit and IT.

The article aims to analyze the impact of IT on financial auditing, which is currently a topic of interest in the global economy. This aspect arises from the analysis of the specialized literature and the related publications, where a predominant interest was found on the Big Data and Big Data Analytics topic, as mentioned in the introduction of this paper. The critical observation applied in this paper consists of rigorous documentation of the debates issued by the professional accounting bodies, which was achieved through an online search of the most recent and concise news/information regarding the effect of Big Data and Big Data Analytics. Scientific articles indexed in international databases were consulted, such as: Emerald Group Publishing, JSTOR, Scopus, Web of Science, Springer Science + Business Media, ScienceDirect, ProQuest, Elsevier, but also the website of the American Accounting Association, the social network Research Gate, Financial Audit Magazine, Semantic Scholar and Google Scholar search engines. An online search of results was done by keywords in both Romanian and English, such as: "audit and technology", "impact of technology in the audit", "financial audit and Big Data", "Data Analytics in the audit", "Challenges in the audit profession".

For this article, only the relevant researches from 20132019 were included, which concerned the impact of BDA in the financial audit. The sorting of articles and publications was accomplished manually, by critically reading their content in advance and including them in this paper, representing the way of specialized works selection. Thus, for the research results are mentioned specialized research, scientific articles, international 
publications and books that have debated and initiated discussions on the current state of emerging technologies.

The present research contributed first to the author's understanding of the emerging technological concepts and secondly, the transposition in an applied way of the acquired information, by mapping the Big Data technologies in the audit profession. As a result of the free discussions conducted with the Big Four specialists and the analysis of the specialized publications, the researcher interpreted the information and tried to understand the vision behind the received answers and the investigated articles. The definition and influence of emerging technologies in the financial audit are commented on throughout this paper. I seek to understand this impact because in the applicative part of this paper the way of working of these technologies is outlined, the logical schemes are represented on this technological process, are detailed key algorithms that compose and develop the present industrial revolution 4.0, but also debates regarding the question "why?" these technologies facilitate the work of the auditor, which is currently extremely timeconsuming.

\section{Results and discussions}

\subsection{Big Data analysis through scientific research and specialized work}

Big Data is based on technologies that converge to meet the extensive demands of information users. Financial auditors could not fully process the amalgamation of data resulting from transactions without the existence of Big Data and Data Analytics tools, in real and accessible time. Despite the outlandish claims of many industry commentators, it is known that many companies are still struggling to understand the Big Data phenomenon. While big companies, Linkedln, Google and Facebook are already working with Big Data, for medium-sized companies, Big Data is a challenge, both in understanding this technology and the decisions to be applied with Big Data (Goes, 2014). The confusion is heightened by the diversity of business solutions and software applications designed to work in the Big Data context. Table no. 1 presents the Big Data influences in the financial audit of literature and specialized publications in chronological order, in order to capture the debates and views on this subject.

\section{Table no. 1. Big Data research in auditing literature and specialized publications}

\begin{tabular}{|c|c|c|c|}
\hline $\begin{array}{l}\text { Research } \\
\text { year }\end{array}$ & Influence on financial audit & Article name & Author \\
\hline 2013 & $\begin{array}{l}\text { - Big Data involves any kind of data, from any kind of source. } \\
\text { - Auditors will initiate new data mining and automation } \\
\text { verification processes. }\end{array}$ & $\begin{array}{l}\text { AIS in an Age of Big } \\
\text { Data }\end{array}$ & $\begin{array}{l}\text { Moffitt, K. C., Vasarhelyi, } \\
\text { M. A. }\end{array}$ \\
\hline 2014 & $\begin{array}{l}\text { - Management still does not understand this technology and } \\
\text { how the organization could be helped. }\end{array}$ & $\begin{array}{l}\text { Big Data and IS } \\
\text { research }\end{array}$ & Goes, P. B. \\
\hline 2015 & $\begin{array}{l}\text { - Big Data is a resource for those who know how to use it. } \\
\text { - Big Data should be adopted by accounting and audit firms. }\end{array}$ & $\begin{array}{l}\text { Consequences of } \\
\text { Big Data and } \\
\text { formalization on } \\
\text { accounting and } \\
\text { auditing standards }\end{array}$ & Krahel, J.P., Titera, W.R. \\
\hline 2015 & $\begin{array}{l}\text { - Big Data development is fundamental in accounting and } \\
\text { auditing processes. } \\
\text { - Big Data development could contribute to changes in } \\
\text { reporting standards. }\end{array}$ & $\begin{array}{l}\text { Big Data in } \\
\text { Accounting: An } \\
\text { Overview }\end{array}$ & Vasarhelyi et al. \\
\hline 2016 & $\begin{array}{l}\text { - Big Data is an invaluable filter for past, potential and future } \\
\text { causal analyzes in financial audit. }\end{array}$ & We are Big Data & Klous \& Wielaard \\
\hline 2016 & $\begin{array}{l}\text { - Big Data will become a necessary technology for auditors. } \\
\text { - Auditors will find that Big Data is inevitable to use, } \\
\text { especially when Big Data is already in the } \\
\text { implementation phase of the client. }\end{array}$ & $\begin{array}{l}\text { Drivers of the Use } \\
\text { and Facilitators and } \\
\text { Obstacles of the } \\
\text { Evolution of Big } \\
\text { Data by the Audit } \\
\text { Profession }\end{array}$ & Alles et al. \\
\hline
\end{tabular}




\begin{tabular}{|c|c|c|c|}
\hline Research & Influence on financial audit & Article name & Author \\
\hline 2018 & $\begin{array}{l}\text { - The analysis conducted by ISACA concludes that Big } \\
\text { Data will change the world. } \\
\text { - However, management does not understand this } \\
\text { technology and how the organization could help. } \\
\text { - The needed skills for Big Data represent a challenge for } \\
\text { users. } \\
\text { - The inability of the auditors to work with Big Data could } \\
\text { lead to a competitive advantage or future professional } \\
\text { opportunities lose. } \\
\text { - The existence of Big Data in the audited companies } \\
\text { implies for the auditors the adoption of the same } \\
\text { business solution applied by the client. } \\
\text { - Using Big Data by both auditors and clients, the audit } \\
\text { process performed will increase the confidence in the } \\
\text { effectiveness of this process and will help to maintain a } \\
\text { closer connection between them. }\end{array}$ & $\begin{array}{l}\text { Data and Data } \\
\text { Analytics Progress } \\
\text { During the Last } \\
\text { Four Years }\end{array}$ & ISACA Journal \\
\hline 2018 & $\begin{array}{l}\text { - A change in accounting and audit standards would add } \\
\text { value and relevance to both economic processes. }\end{array}$ & $\begin{array}{l}\text { Big Data and } \\
\text { Changes in Audit } \\
\text { Technology: } \\
\text { Contemplating a } \\
\text { Research Agenda }\end{array}$ & $\begin{array}{c}\text { Salijeni, G., Samsonova, T. } \\
\text { A., and Turley, S. }\end{array}$ \\
\hline 2018 & $\begin{array}{l}\text { - Although the Big Data system involves multiple benefits } \\
\text { through its characteristics (i.e. volume, variety, speed } \\
\text { and veracity), the audit profession has hardly adopted } \\
\text { this concept. }\end{array}$ & $\begin{array}{c}\text { Big Data in } \\
\text { Accounting and } \\
\text { Finance: A Review } \\
\text { of Influential } \\
\text { Publications and a } \\
\text { Research Agenda }\end{array}$ & Gepp et al. \\
\hline 2019 & $\begin{array}{l}\text { - The structured information Big Data is only a fragment of } \\
\text { the infinite universe of data (unstructured, semi- } \\
\text { structured). }\end{array}$ & $\begin{array}{l}\text { Audit and } \\
\text { technology }\end{array}$ & ACCA \\
\hline
\end{tabular}

Source: Author's processing

\subsection{Big Data architectures and technologies through Apache Hadoop}

As a result of Big Data implementation, Big Data Cloud analysis can be performed using Apache Hadoop, a constantly developing technology that offers adaptability to companies in modern times. Hadoop is a set of opensource software utilities for Cloud Computing, which stores data in a distributed manner and in massive quantities, processing them in parallel. This allows the use of a network of multiple computers, which solves problems sent by the client. The input data is divided into $128 \mathrm{Mb}$ blocks and then moved to different nodes (i.e. computers). Since all data blocks are stored on data nodes, the user can start processing the data. Then, the resource manager schedules the transmission of data received from the user on individual nodes. Finally, after all the nodes process the data, the output is written back to HDFS (i.e. data warehouse), via MapReduce, being the data processing engine, specifically the Hadoop clusters implemented for Big Data applications. MapReduce program consists of running two functions, also called: Map and Reduce, pillars that ensure the processing of data stored in HDFS. The advantages of MapReduce are the processing of huge amounts of (raw) data at phenomenal speed, the elimination of duplicates, the ability to process a multitude of data in parallel. Due to its unique scalability property, MapReduce can run on thousands of nodes, without compromising data analysis performance.

Returning to HDFS, it offers 2 different audit logs: hdfsaudit.log - used for the auditor's general activity and SecurityAuth-hdfs.audit - for the audit activity of the authorization. Configuring these logistics files involves connecting to security logs. An experiment was 
undertaken by Ahmad et al. (2019), where existing audit logs were used to verify the BlockTrail prototype on the Blockchain network. The level of correctness and consistency was verified at the level of this network through audible events, which shows different actions performed, such as status, creation, permission setting, document renaming. Logs from logs show username, recipient of order execution, date of execution of an order, IP address and other information. Figure no. 1 presents the HDFS functionality that could be mapped in the financial audit missions.

\section{Figure no. 1. HDFS functionality mapped in financial audit missions}

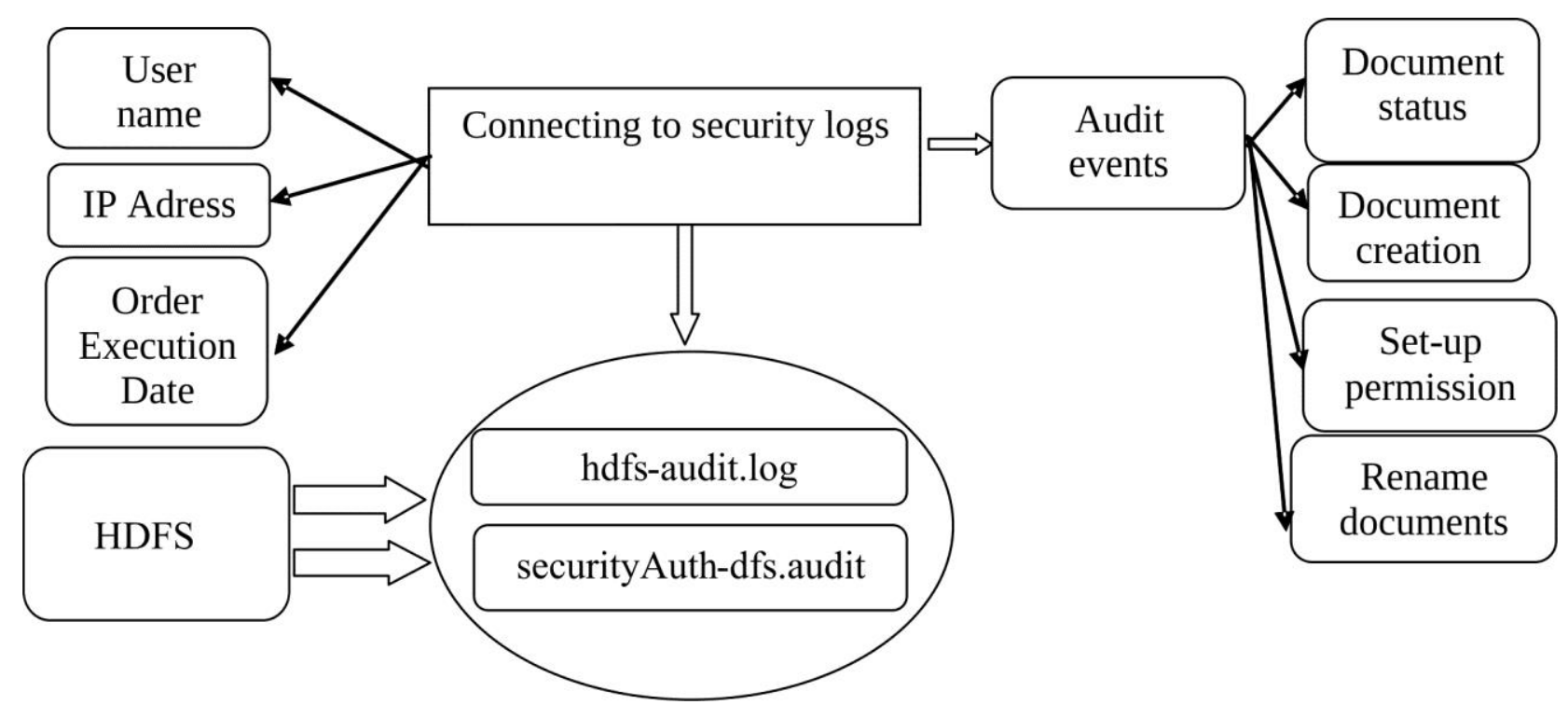

Source: Author's processing

Also, all failed access attempts are logged. By verifying audit logs, unusual transactions or unsuccessful attempts to connect to the audited company database could be detected. These results are variables that require examination and could have as main causes: failure to update the internal working procedures (the user who logged in has access rights but were not granted by the IT department), the existence of faulty management (insufficient knowledge of HDFS) or the inadequate computer software use (incorrect implementation of the two audit logs).

Another advantage for financial auditors is that Hadoop own tolerance error, resumes the command and allows security analysis and storage of Advanced Persistence Threats (APT) to deepen available security tools. The Hadoop provides a response to "blocks" on the cluster, identifies the similar data groups and distributes the processed data by dividing that command into a series of independent tasks. These tasks run in parallel on the computer cluster, thus increasing the amount of data analyzed by obtaining a shorter time and varied processing. In Figure no. 2 is graphically presented the utility of Hadoop in the financial audit, by connecting to the security logs and possible causes that led to anomalies in the operational processes. 


\section{Figure no. 2. Implications of connecting to security logs}

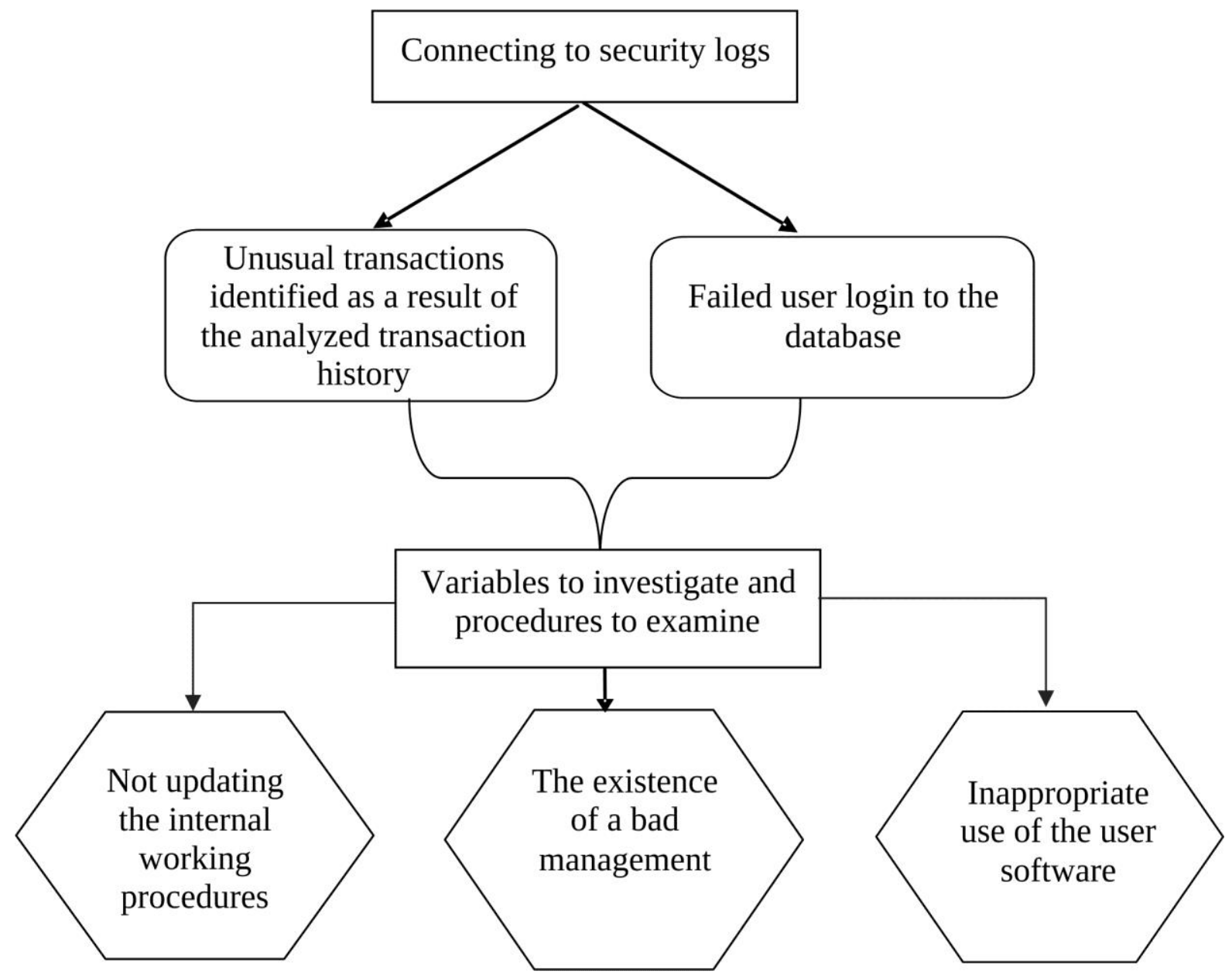

Source: Author's processing

\subsection{Architectures and Big Data technologies - SQL and NoSQL}

Running SQL on Hadoop allows the application of similar SQL techniques, namely running queries, which makes it extremely versatile and easy to use in data analysis. Users expect Hadoop SQL technologies to support common Business Intelligence tools, such as Tableau and MicroStrategy platforms for data visualization, custom technical analysis, conversion of CSV and PDF reports, or Excel and Access files. From my point of view, the auditors should incorporate this technology in the audit missions, taking into account the offered tools, efficiency and speed for processed data.
The execution time of SQL queries on Hadoop range from milliseconds to minutes, depending on the complexity of the query, analyzing a smaller amount of data in more detail.

NoSQL summarizes very large data sets, from nonrelational or distributed databases, opposite to SQL where data are found under structured databases. NoSQL helps to analyze unstructured data and store data in several ways: document-oriented databases (e.g. MongoDB, CouchDB), column-based, graphical representation (e.g. Neo4j, GiraffeDB) or organized as a KeyValue store (e.g. Redis, Cassandra, MemcacheDB). NoSQL offers flexibility by creating documents that do not have a previously defined structure. The use of 
NoSQL provides a unique structure for each document. NoSQL has appeared as a necessity for a simpler design and due to its horizontal scalability (i.e. the ability of a system to support a large volume of data by adding more computing devices to the system). NoSQL is preferred when working with huge amounts of data or in real-time web applications (i.e. transactions, notifications, SMS alerts), greatly improving response time.

The inclusion of NoSQL in the financial audit analysis performed would allow the structuring of the non-rational data in a unique way, conceived by the auditor. Many commands in the operating system become automatic by accessing the "sort" or "find" commands and innumerable other UNIX shell utilities, which are useful in the command line interface between the user and the operating system. Big Data could be structured in various ways, due to the flexibility offered by this storage mechanism. Studying the data and modelling it would allow a personalized professional judgment achievement. The possibility of collecting data from multiple sources and analyzing them, without needing structured data, provides the auditor extended perspectives for detailed analysis (where appropriate), as well as an imaginative projection in proposing solutions to improve processes. Table no. 2 presents the SQL and NoSQL properties, which could be compared and examined so that the appropriate mechanism for the audit mission type is adopted.

\section{Table no. 2. The SQL and NoSQL properties}

SQL (Structured Query Language)

The programming language that allows writing queries, writing and executing certain syntax (SELECT, FROM, WHERE, GROUP BY) and including existing parameters in fields/columns

Structured or relational database

It already implies a certain schema, called fields/columns containing data

Users could work with several tables, because of the relationship between them

Horizontal scalability is impossible to achieve. Vertical scalability is possible

Restrictive in large data analysis, but allows to run quickly queries, on smaller data sets
NoSQL (Not only Structured Query Language)

Summarizes very large data sets, in real-time. For example, ID, quantity, price, location are data that are contained in databases, (in some cases) as duplicates

Non-rational or distributed databases

It does not already involve a schema. Due to its flexibility, data could be added anytime and anyway

There is no relationship between data, but these relationships could be created manually

Both horizontal and vertical scalability are possible

Suitable for financial audit missions because large volumes of data could be read and explored, with flexibility in selecting the database

Source: Author`s processing

Big Data allows access to information in different extended format and $100 \%$ verification of the company's transactions (IAASB, 2017), surpassing the sample testing. With the Computer Assisted Auditing Techniques (CATT) help, the auditor analyzes the transactions in its entirety, and the company's image is substantially more relevant, qualitative and reliable. CATTs (e.g. Caseware IDEA, ACL, Pentana) allow the verification of a large volume of data managed in order to identify risks, inconsistencies and errors, implicitly offering a broader view on the audited financial processes. Tens of thousands or millions of transactions could be sorted, filtered and analyzed (Stanciu, 2015), facilitating the discovery of high-risk items (KPMG, 2018; ACCA, 2019). In the audit process, CAAT became synonymous with the concept of Data Analytics, a term that will be discussed during this paper. Through efficient use of intelligent Data Analytics solutions, a major innovation for the auditors is expected, methodologically and professionally (KPMG, 2018). Above were identified studies, process schemes, advantages and comparisons of the support provided by Big Data, such as: describing a spectacular growth of data that complements many of the traditional analyzes, possible changes in the international accounting (IAS) and audit (ISA) standards due to a new way of working, necessary skills for interpretation (HDFS audit logs) and choice of data retrieval mechanism (SQL vs. NoSQL). As a result, Big Data contributes to a complete analysis. Achieving this goal also requires (in a time) useful 
processing. This fast, varied processing is due to the emergence of Big Data Analytics.

\subsection{Big Data technologies - Data Analytics}

A first perspective suggests changes in the audit methodology and maybe even in a radical way. The BDA changes the traditional way of auditor's working and brings various changes at the professional level, consisting of new approaches to the working procedure regarding the carrying out of the audit missions, the change of the methodology in audit, connection to (Project) Server in order to manage the audit project and remote (IT) support that allows the connection and communication with the client from distance. The ability to verify and work with large volumes of data brings innovation to the auditor's profession. In this way, an adaptation to smart data is highlighted (KPMG, 2018). The term smart data is based on intelligent data processing algorithms that help interpret past, present and future transactions and provide a solid basis in making effective strategies for making the best decisions. The presence of two important filters in the audit is particularly important: the Al and the professional reasoning of the financial auditor, rather than by applying Al in a singular way (Klous \& Wielaard, 2016). Al software tools help extract information based on keywords. Thus, it is not only easy to process data and create state-of-the-art software, but also to understand human behavior, a fascinating vision with far-reaching consequences for auditors.

The second perspective is that the audit methodologies should not necessarily be adapted to Big Data. In fact, here we find a divergence with the specialized literature discussed so far in this paper. This view is supported by the fact that a traditional audit methodology could be just as important to follow, so there is no need for innovation in this direction (KPMG, 2018). The explanation of this vision is that based on a quality audit there will be a detailed analysis of data and performance indicators. For the financial auditor, question marks can be raised when discrepancies are found between the amounts presented in the financial statements, being unexpectedly lower or higher than they were commonly reported. The analysis of these data should be delegated to the experienced auditor, who understands the significance behind the figures and has the ability to interpret/predict possible strategic risks. The process of data analysis and interpretation requires increased attention. There may also be a tendency to overuse current auditor technologies, with important details being overlooked regarding already acquired knowledge, past experience or business understanding. These issues concern the skeptical reasoning of the financial auditor (already in charge), not involving emerging technological tools.

For financial audit missions, the observations made above find their correspondent in the huge potential offered by Big Data (Stanciu, 2015), but neither can the impact of BDA integration be ignored (Appelbaum, 2017; Krahel \& Titera 2015; Ramamoorti et al., 2016, Vasarhelyi et al., 2015). According to ACCA (2019), Big Data Analytics is the most widely used technology, being present in most companies, which cannot be said about Machine Learning, a technology that is just in the implementation stage. Data Analytics and operational process automation are working techniques used significantly in audit missions (Vasarhelyi et al., 2015; Alles et al., 2006). Investor expectations are that these new, sophisticated technologies will become widely implemented, while also following a redefinition of the auditing profession (Rozario \& Thomas, 2019). There are companies (Big Four) that already use Data Analytics in the audit tests and the processes of testing the validity of transactions, analysis and reconciliation between accounting accounts, replacing the classic methods of testing. The Guru99 website (2019) ranks the best Big Data Analytics tools for 2020, including: Xplenty, Microsoft HDInsight, Skytree, Talend, Splice Machine, Spark, Plotly, Apache SAMOA.

FinancesOnline believes that the main Data Analytics 2020 software, in descending order, are: Sisense, Looker, Yellowfin, Zoho Analytics, Periscope Data.

Periscope Data highlights trends-based results, interactive presentations, and dashboard-like graphics. Sisense is number 1 in Data Analytics, with a 99\% consumer satisfaction ratio due to the variety of options offered (e.g. custom dashboards, interactive results visualization, easy detection of analytical trends and models) and Machine Learning applicability. The second place is the Looker, which allows the extraction of data from multiple sources and then transfer to a SQL database, which is subjected to processing before reaching the auditors' attention. The advantage of this Data Analytics tool is that it can schedule data delivery to any other access source, such as: chat, email, webhook, File Transfer Protocol (FTP), a type of 
protocol that allows access to data or files stored on servers.

According to PwC (2019), the potential of Data Analytics, RPA (Robotic Process Automation) and Al (Artificial Intelligence) technologies will be observed in 2-3 years. Data Analytics is the most widely used technology in auditing and allows the identification of new analytical methods, contributes to cost-effectiveness and better decision-making and testing tens of thousands of transactions (ACCA, 2019). Despite the benefits offered, the pace at which things are evolving is slower than expected five years ago (ISACA, 2018 a). Table no. 3 allows an overview of the most representative debates, surveys and specialized research on (Big) Data Analytics.

\section{Table no. 3. Research Big Data Analytics in the auditing literature and specialized publications}

\begin{tabular}{|c|c|c|c|}
\hline $\begin{array}{l}\text { Research } \\
\text { year }\end{array}$ & Influence on financial audit & Article title & Author \\
\hline 2013 & $\begin{array}{l}\text { - Predictive analytics are grounded in Data Analytics, } \\
\text { proving to be an investment worth adopting. } \\
\text { - Data Analytics allows access to interesting models of } \\
\text { analysis, trends and exceptions in the audit. }\end{array}$ & $\begin{array}{c}\text { Predictive audit } \\
\text { analytics: evolving to a } \\
\text { new era }\end{array}$ & Kuenkaikaew, S. \\
\hline 2017 & $\begin{array}{l}\text { - The quality of the financial audit could be completely } \\
\text { ensured and even improved by implementing and } \\
\text { developing Data Analytics (e.g. analyzing the models } \\
\text { behind the transactions, extracting information and } \\
\text { stating conclusions, thorough research of } \\
\text { inconsistencies, anomalies at the accounting process } \\
\text { level). }\end{array}$ & $\begin{array}{l}\text { Exploring the Use of } \\
\text { Technology in the } \\
\text { Audit, with a Focus on } \\
\text { Data Analytics }\end{array}$ & IAASB \\
\hline 2017 & $\begin{array}{l}\text { - At the level of modern audit commitments, there is a } \\
\text { need to make advanced predictions. } \\
\text { - Big Data Analytics allows companies to stay competitive. } \\
\text { - The logical reasoning of the auditor will know a } \\
\text { professional extension. }\end{array}$ & $\begin{array}{l}\text { Big Data and Data } \\
\text { Analytics in the } \\
\text { Modern Audit } \\
\text { Engagement: } \\
\text { Research Needs }\end{array}$ & $\begin{array}{l}\text { Appelbaum, D., Kogan, } \\
\text { A., Vasarhelyi, M. }\end{array}$ \\
\hline 2018 & $\begin{array}{l}\text { - Most organizations have started working with Data } \\
\text { Analytics. } \\
\text { - Data Analytics is a trend that is developing faster in the } \\
\text { current period, compared to the last period. }\end{array}$ & $\begin{array}{l}\text { Data and Data } \\
\text { Analytics Progress } \\
\text { During the Last Four } \\
\text { Years }\end{array}$ & ISACA Journal \\
\hline 2018 & $\begin{array}{l}\text { - Big Data Analytics has a competitive advantage in } \\
\text { accounting and in general, in the financial sector, } \\
\text { favoring the decision-making process, fraud prevention } \\
\text { and detection, verification and analysis of customer } \\
\text { information. }\end{array}$ & $\begin{array}{l}\text { Big Data Opportunities } \\
\text { for Accounting and } \\
\text { Finance Practice } \\
\text { and Research }\end{array}$ & Cockcroft et al. \\
\hline 2018 & $\begin{array}{l}\text { - Data Analytics facilitates continuous auditing and real- } \\
\text { time auditing, followed by establishing analytical models, } \\
\text { identifying errors, extracting useful information and } \\
\text { formulating the audit opinion. }\end{array}$ & $\begin{array}{l}\text { Audit Risk Alert: } \\
\text { General Accounting } \\
\text { and Auditing } \\
\text { Developments } \\
\text { 2018/19 }\end{array}$ & AICPA \& CIMA \\
\hline 2018 & $\begin{array}{l}\text { - Big Data Analytics facilitates the discovery of potential } \\
\text { errors by } 100 \% \text { testing the huge volume of data, sorting, } \\
\text { filtering and analyzing all transactions. }\end{array}$ & The future of audit & KPMG \\
\hline
\end{tabular}

Source: Author's processing

\section{Conclusions}

Technology has penetrated all sectors of the economy, and auditing is no exception. Auditors are already constrained by technological developments, as are all other areas of this world (e.g. medicine, marketing, construction, the renewable energy sector). This research has shown how the impact of IT can cause 
changes in the information circuit, in the procedures and tests applied by financial auditors, through the adoption of Big Data and Big Data Analytics.

Big Data brings to analysis information of any kind: structured, unstructured or semi-structured, but which can be analyzed in a complete manner, which proposes avoiding risks, detecting fraud and identifying material errors. Since the technology allows for a full test of financial information, Data Analytics applies to a wealth of huge information (i.e. Big Data). Technological changes require better financial management for financial auditors. The research includes projects from Big Data and Big Data Analytics, "collected" through fundamental and qualitative research. In the context of understanding these technologies, ERP platforms, Cloud Computing platforms, the concept of Audit IT, Apache Hadoop, HDFS and Map Reduce, SQL and NoSQL, CATT, emerging technological tools that, without just and maybe, could lead to automation were analyzed and studied. on a large scale, contributing to a comprehensive analysis of the Big Data phenomenon, in fact, existing in all large companies.

At the Big Four companies' level, with the appropriate Big Data tools help, projections were detailed on how to allow complete audits in a shorter time, even though increasing volumes of information are reported, as the day goes by. Progressively, financial auditors cover more of the audit activity with a lower level of effort, adding value to this process. In the Big Data context, companies can develop an internal approach aimed at adopting measures that will face the new challenges related to data integrity, security and analysis, starting from the following actions:

- Use of existing applications for rapid implementation in the organizational system;

- Training of internal staff at the expense of hiring expensive contractors;

- Closer collaborations with stakeholders to substantiate the business strategy;

- Implementation of a hybrid data ecosystem (i.e. management, forecasting and use of IT systems).

Apache Hadoop, Big Data technology, has proven itself to fold on financial audit missions. Because it allows the analysis of this phenomenon (i.e. Big Data) in the Cloud, Hadoop offers adaptability to the companies that choose to implement this technology. This research has demonstrated through logical projection schemes such as Big Data via HDFS and Map Reduce that it is possible to track audit logs so that the auditor easily and securely verifies information about the company's transactions. The advantages of MapReduce consist of the huge processing of (raw) data at a phenomenal speed and in parallel, eliminates duplicates. Through Apache Hadoop, unsuccessful access attempts can be checked and unusual transactions detected. Moreover, security analyzes can be undertaken and the desired commands can be resumed if an error has occurred.

In addition to the aforementioned points, which are based on the fundamental research method, the research denotes and critical observation, in the sense that only specialized research/reports debating Big Data and Data Analytics were included for this paper. With the ever-deeper integration of technology, the manual and repetitive tasks (eng. Ticking and bashing) will disappear, being replaced by the BDA effect that revolutionizes the business world. At the same time, these advantages offered by technology have many interpretations. If IT development makes it possible to increase the efficiency of audit missions in a substantial way, shouldn't there be a dramatic increase in costs for extending this goal? It seems not. The price of technology is decreasing as the benefits increase. There is an indirect relationship between technology and the advantages offered. The technology brings the auditor face-to-face with a professional redefinition, which promises easier data management, total testing of company transactions, implementation of test models through Apache Hadoop and understanding of Data Analytics software. These technological effects lead to the redefinition of audit processes based on lower costs and a smarter way of working. These observations are his correspondent in the work of Rozario \& Thomas (2019).

The present research also considered qualitative research by highlighting the literature, but also projections, models, demonstrations, applications of the new technological instruments that could be included in the financial audit missions, but which did not reach a general peak (integration and working entirely with and through the new technological tools). The article also describes the practical part, which is based on discussions with audit and IT specialists from Big Four companies, more precisely how the auditor's routine work is taken over by computer software based on the BDA concept. 
IT will not be able to substitute the actions of the human being, which is responsible for deep thinking and analysis, which defines the selection criteria. So, without the human expert, computing would not be able to progress. No matter how many (paradigm shifts) technology promises, professional judgment will always be needed in the audit. IT will not be able to (ever) provide everything an auditor needs to know, for example, it cannot extract false information from the data provided by companies. The value of human capacity contributes to the experience and judgment in the audit, regardless of the IT benefits. At this time, the models predefined by the auditors facilitate the analysis of the data, the making of predictions and the preparation of the audit reports. In addition to Big Data, there is other information that auditors should consider, for example: information history of the audited entity, views on the industry in which it operates, competition, audit reports from past audits. The sampling method, on various selection criteria (e.g. at the level of sum, filtering depending on the complexity of the transactions) will cease to be used or at most discussed.

In this paper were presented aspects regarding the possibility of $100 \%$ data analysis through advanced IT tools Data Analytics, which highlights the technological developments that tend to adopt a continuous audit, due to the automation and the complete verification of transactions. When applying Data Analytics, several top tools (e.g. Sisense, Looker, Yellowfin, Zoho Analytics, Periscope Data) can be mentioned. With such a diverse range of Data Analytics software, the auditor profession will revolutionize completely. Mapping them on audit missions is the first step towards a new, more technologized and efficient approach, such as: analyzing suspicious transactions resulting from inconsistencies in the income and expense accounting accounts, how to use the expenditures between years $\mathrm{N}-1$ and $\mathrm{N}$, values of expenses and revenues that significantly exceed the previous financial situation reported, total invoices that do not match the balance in the balance sheet. It is certain that everything that is delegated from current or so-called ordinary transactions will be concerned with the professional reasoning of the auditor, these representing work tasks that fall to the human factor. This is the point where the most careful analysis of the data comes in, the financial auditor being the one who analyzes those suspicious transactions extracted from the software. In this way, causes are determined, but also possible diagnoses: error (material), (attempt of) fraud or unusual transaction.
NoSQL has proven to be another type of technology that can facilitate the work tasks of auditors. NoSQL has the ability to summarize very large sets of data, in real-time, on non-national databases and requiring a certain data schema. Even if the data source is a varied one, it is up to the auditor to apply the professional reasoning for modelling the audit model. Auditors must embrace numerous working techniques based on NoSQL, Hadoop Apache or at least first instance connection to these technologies and then mapping the data obtained on Machine Learning, a technology that will be discussed and mapped in a subsequent article.

This paper showed the functioning of the emerging technologies, the algorithms behind the BDA, but also the transposition into the financial audit missions. Auditors need to be aware of working with Big Data and Data Analytics and how they can maximize the huge potential they offer. Combined with professional reasoning, experience and critical thinking, emerging technologies promise changes in the financial auditor profession. The impact of IT is also felt at the level of junior auditors, who are just beginning their audit career. They will need to be intensely documented about the new technologies and the functionality of the business, in order to understand the newly emerging technological instruments and to acquire the skills needed for a quality audit, at the senior level. With an increasingly intense tendency towards automation, success does not seem impossible to achieve.

The present paper also aspires to present other aspects that could be considered for the audit profession, namely the advantage that all parties involved would benefit if closer collaboration between organizational staff was adopted. The applicability would consist of a direct contact of the financial audit department with the accounting and internal audit department, which would provide a broader view on the critical risk areas and a stronger connection between these professions. Linking the occurrence of risk with company transactions, followed by risk assessment (fraud) would know early management and anticipation of economic trends (i.e. the emergence of other technologies, the development of new economic trends, the adoption of business strategies).

The ability to look in perspective, the development of a healthy professional judgment represents future perspectives for this profession. Auditors are advised to turn their attention to understanding the current 
technological trend, but also what is expected to follow. In order to develop the technical skills that auditors are required to acquire, this paper recommends proactive attitude, critical thinking, professional skepticism (i.e. an auditor's muse quality), an open mind to challenges and a developed financial curiosity. An important aspect must be considered: complex financial audit missions should be conducted by auditors with the necessary experience and skills. Adapting the entire corporate reporting system to a documented level towards IT, together with a qualification of directors, administrators and auditors are imperative in these technological developments. Along with emerging technologies, the audit would provide important stakeholders with key controls and access to service quality. In addition to investing in training and working with the right people, investments in new technologies (which will surely revolutionize the near future) will complete a quality financial audit.

\subsection{Exclusively conclusions for Romania}

By positioning this work in the (development space) industrial revolution 4.0, working with the technologies presented throughout this paper is important to become known to the financial audit in Romania. Auditors need to be aware of the benefits and risks generated, mainly towards data theft. On the professional level, the poor preparation in the analysis of transactions, which is increasingly prone to automation, represents another impasse that must be overcome by the auditors in our country. The process of data analysis would require a higher degree of expertise in order to balance human resources with the impact of information technology. It is essential to strengthening the professional judgment by contributing to emerging technologies and focusing on identified risk elements. Generally, the regulatory authorities in Romania should take into account extensive information, extended guidance and rigorous control campaigns to ensure that the financial auditors in
Romania are truly informed and know in detail, at an experienced level, the work with these emerging technologies.

\subsection{Future research directions}

For future work, it is possible to take into account the research of the situation existing in some countries such as Switzerland, Italy, which have already adopted the technologies presented throughout this article, but also the extension of research at the level of public institutions, where the degree of implementation of the technologies emergent is experiencing a late-onset, produced by people's resistance to change.

The undertaken fundamental-qualitative research could be continued later by applied research, in order to demonstrate the practical impact of IT by mapping the new technologies on the financial audit missions in the daily work, starting from the models outlined in this paper. Auditors can track the actual flow of audit missions and implement BDA in a comprehensive manner for testing and technological learning, both in the private and public sectors. The author will initiate quantitative research in this regard, by conducting a survey with the authorized auditors in Romania, registered in the electronic public register ASPAAS.

\subsection{Research limitations}

The present qualitative research considered the impact of IT not only in the audit but also in some sections of this article, on accounting, following the connection between these professions. The technologies analyzed could also be applied to other financial fields (e.g. business expertise, business evaluation, internal audit, financial reporting, business consulting), this aspect contributing to the limitations of this paper. Discussions with audit and IT specialists, and not with managers with a broader view of business processes, could be the second limitation of this article.

\section{REFERENCES}

1. Ahmad, A., Saad, M., Njilla, L., Kamhoua, C. Bassiouni, M., Mohaisen, A. (2019). BlockTrail: A Scalable Multichain Solution for Blockchain-Based Audit Trails, 2019 IEEE International Conference on Communications (ICC), pp. 1-6
2. Alles, M. G. (2015). Drivers of the use and facilitators and obstacles of the evolution of Big Data by the audit profession, Accounting Horizons, Vol. 29, No. 2, pp. 439-449 
3. Appelbaum, D., Kogan, A., Vasarhelyi, M. (2017). Big Data and Data Analytics in the Modern Audit Engagement: Research Needs. AUDITING: A Journal of Practice \& Theory, Vol. 36, No. 4, pp. 1-27

4. Bhaskar, K., Flower, J. (2019). Financial Failures and Scandals: From Enron to Carillion, Routledge Focus, London

5. Cockcroft, S., Russell, M. (2018). Big Data Opportunities for Accounting and Finance Practice and Research: Big Data in Accounting and Finance. Australian Accounting Review, Vol. 28, No. 3, pp. 323-333

6. Chan, D.Y., Chiu, V., Vasarhelyi, M.A. (2018). Continous Auditing: Theory and Application. Series on Big Data, Analytics and Artificial Intelligence applied to Accounting and Auditing, Emerald Publishing, United Kingdom

7. Dilla, W., Janvrin, D. J., Raschke, R. (2010). Interactive data visualization: New directions for accounting information systems research, Journal of Information Systems, Vol. 24, No. 2, pp. 1-37

8. Farcane, N., Deliu, D. (2020). Stakes and Challenges Regarding the Financial Auditor's Activity in the Blockchain Era, Audit Financiar, Vol. XVIII, No. 1(157)/2020, pp. 154-181

9. Fiammetta, S.P. (2017). Bitcoin and the Blockchain as Possible Corporate Governance Tools:

Strengths and Weaknesses, PennState Journal of Law and International Affairs, Vol. 5, No. 1, pp. 262

10. Gartner (2019). Why Audit Leaders Need to Adopt RPA, available online:

https://www.gartner.com/smarterwithgartner/whyaudit-leaders-need-to-adopt-rpa/ (accessed at 3.01.2020)

11. Gepp, A., Linnenluecke, M., O'Neill, T., Smith, T. (2018). Big Data in Accounting and Finance: A Review of Influential Publications and a Research Agenda, 4th Forensic Accounting Teaching and Research Symposium, Vol. 40, pp. 102-115

12. Goes, P. B. (2014). Big Data and IS research, available online: https://misq.org/misq/downloads/ download/editorial/603/ (accessed at 7.11.2019)

13. Janvrin, D., Wood, D. (2016). The Journal of Information Systems 2015 Conference on Information Technology Audit, Journal of Information Systems. Vol. 30, No. 1, pp. 3-5
14. Johnson, S. (2018). Human-like A.I. will emerge in 5 to 10 years, say experts, available online: https://bigthink.com/surprising-science/computerssmart-as-humans-5-years (accessed at 11.12.2019)

15. Klous, S., Wielaard, N. (2016). We are Big Data: The Future of the Information Society, Atlantis Press

16. Krahel, J.P., Vasarhelyi, M. A. (2014). AIS as a Facilitator of Accounting Change: Technology, Practice, and Education, Journal of Information Systems, Vol. 28, No. 2, pp. 1-15

17. Krahel, J.P., Titera, W.R. (2015). Consequences of Big Data and formalization on accounting and auditing standards, Accounting Horizons, Vol. 29, No. 2, pp. 409-22

18. Kuenkaikaew, S. (2013). Predictive Audit Data Analytics: Evolving to a New Era. PhD dissertation, Rutgers Business School, Newark

19. Moffitt, K. C., Vasarhelyi, M. A. (2013). AIS in an Age of Big Data, Journal of Information Systems, Vol. 27, No. 2, pp. 1-19

20. Moffitt, K. C., Rozario, A. M., Vasarhelyi, M. A. (2018). Robotic Process Automation for Auditing, Journal of Emerging Technologies in Accounting, Vol. 15, No. 1, pp. 1-10

21. Omoteso, K., (2016). Audit effectiveness: Meeting the IT challenge, Routledge

22. Pathak, J., Chaouch, B., Sriram, R. S. (2005). Minimizing cost of continuous audit: Counting and time dependent strategies, Journal of Accounting and Public Policy, Vol. 24, No. 1, pp. 61-75

23. Ramamoorti, S., Agarwal, A., Nijhawan, S. (2016). Big Data and continuous monitoring: A synergy whose time has come?, Internal Auditing, Vol. 31, No. 1, pp. 19-26

24. Rîndaşu, S.M. (2016). Information security - a new challenge for the young and future financial auditors, Audit Financiar, Vol. 14, No. 6 (138)/2016, pp. 670-679

25. Rooney, H., Aiken, B., Rooney, M. (2017). Q\&A. Is Internal Audit Ready for Blockchain?, Technology Innovation Management Review, Vol. 7, No. 10, pp. 41-44

26. Rozario, A.M., Thomas, C. (2019). Reengineering the Audit with Blockchain and Smart Contracts, 
Journal of Emerging Technologies in Accounting, Vol. 16, No. 1, pp. 21-35

27. Saha, B., Srivastava, D. (2014). Data quality: The other face of Big Data, IEEE 30th International Conference on Data Engineering, pp. 1294-1297

28. Salijeni, G., Samsonova, T. A., Turley, S. (2018). Big Data and Changes in Audit Technology: Contemplating a Research Agenda, Accounting and Business Research, Vol. 49, No. 1, pp. 95-119

29. Schmitz, J., Leoni, G. (2019), Accounting and Auditing at the Time of Blockchain Technology: A Research Agenda, Australian Accounting Review, Vol. 29, No. 2, pp. 331-342

30. Stanciu, V. (2015). Consideratiii privind auditul financiar în era Big Data, Audit Financiar, Vol. 13, No. 8 (128)/2015, pp. 3-9

31. Vasarhelyi, M., Kogan, A., Tuttle, B. (2015). Big Data in Accounting: An Overview, Accounting Horizons, Vol. 29, No. 2, pp. 389-96

32. Yermack, D. (2017). Corporate Governance and Blockchains, Review of Finance, Vol. 21, No. 1, pp. 7-31

33. ACCA. (2019). Audit and technology, available online:

https://www.accaglobal.com/content/dam/ACCA_G lobal/professional-insights/audit-and-tech/pi-auditand-technology.pdf (accessed at 1.11.2019)

34. AICPA. (2015). Audit Data Analytics and Continuous Audit: Looking Toward the Future, available online: https://www.aicpa.org/interestareas/frc/assurancea dvisoryservices/downloadabledocuments/auditData Analytics_lookingtowardfuture.pdf (accessed at 02.11.2019)
35. AICPA \& CIMA. (2018). Audit Risk Alert: General Accounting and Auditing Developments 2018/19, available online:

https://books.google.ro/books?id=Rpg9DwAAQBAJ \&printsec=frontcover\&dq=inauthor:\%22AICPA $\% 22$ \&hl=ro\&sa=X\&ved=0ahUKEwi81_vQzoDnAhVBZIA $\mathrm{KHehxAecQ6AEIKDAA \# v=onepage \& q \& f=false}$ (accessed at 2.01.2020)

36. IAASB (International Auditing an Assurance Standards Board) (2017). Exploring the Use of Technology in the Audit, with a Focus on Data Analytics, available online: https://www.iaasb.org/publications/exploringgrowing-use-technology-audit-focus-data-analytics (accessed at 7.10.2019)

37. ISACA Journal (a) (2018). Data and Data Analytics Progress During the Last Four Years, Vol. 5, available online: https://next.sit.isaca.org/resources/isacajournal/issues/2018/volume-5/data-and-analyticsprogress-during-the-last-four-years (accessed at 11.11.2019)

38. ISACA Journal (b), (2018). Impacts of Blockchain on the Auditing Profession, Vol. 5, available online: https://www.isaca.org/Journal/archives/2018/Volum e-5/Pages/impacts-of-Blockchain-on-the-auditingprofession.aspx (accessed at 11.11.2019)

39. KPMG. (2018). The future of audit, available online: https://assets.kpmg/content/dam/ kpmg/uk/pdf/2018/01/the-future-of-audit.pdf (accessed at 15.10.2019)

40. PwC. (2019). Future of audit, available online: https://www.pwc.co.uk/who-we-are/future-ofaudit/pwc-future-of-audit-report-july-2019.pdf (accessed at 25.10.2019) 